\title{
Naval Architecture: From Theory to practice
}

\author{
Arquitectura Naval: De la Teoría a la Práctica
}

DOI: https://doi.org/10.25043/19098642.186

\author{
Richard Luco Salman ${ }^{1}$ \\ Rodrigo Flores Troncoso ${ }^{2}$ \\ Rodrigo Baos Ortiz ${ }^{3}$
}

\begin{abstract}
The complexity of projecting and designing a ship requires a work sequence that covers at least three main areas: (1) Concept engineering; (2) Basic engineering; (3) Detail engineering. This paper explains the design transition that exists (or should exist) between concept engineering and the final product, emphasizing the existing contractual relationship with the shipbuilder, especially in the initial definition of the project and the influence on construction aspects.
\end{abstract}

Key words: Design; naval architecture; mission profile; shipbuilding.

\section{Resumen}

La complejidad del proyecto y diseño de una embarcación obliga a plantear una secuencia de trabajo que abarca al menos tres grandes áreas: (1) Ingeniería de concepto; (2) Ingeniería básica; (3) Ingeniería de detalle. El presente trabajo explica la transición de diseño que existe (o debería existir) entre la ingeniería de concepto y el producto final, poniendo énfasis en la relación contractual existente con el armador, especialmente en la definición inicial del proyecto y la influencia sobre los aspectos constructivos.

Palabras claves: Diseño; arquitectura naval; perfil de misión; construcción naval.

Date Received: January 20 2019 - Fecha de recepción: Enero 20 de 2019

Date Accepted: March 3 ${ }^{\text {rd }} 2019$ - Fecha de aceptación: Marzo 3 de 2019

\footnotetext{
${ }^{1}$ Dr. Marine Eng., Instituto de Cs. Navales y Marítimas, Universidad Austral de Chile. Valdivia, Chile. Email: rluco@uach.cl

${ }^{2}$ Chief of Naval Architecture, NavTec Ltda. Valdivia, Chile. Email: rflores@navtec.cl

${ }^{3}$ Numerical Hydrodynamic Area, NavTec Ltda. Valdivia, Chile. Email: rbaos@navtec.cl
} 


\section{Introduction}

The development of a naval architecture project, unlike a traditional project, requires taking into consideration the complexity existing in the autonomy that a final work must have, in the broadest meaning of the word. The basic premise of the initial approach must ensure that the project must be capable of complying with construction and regulatory requirements, which on are often contradictory (especially in special ships), either due to the safety of human life at sea or simply due to aspects related to physics and mathematics.

Therefore, it is important to correctly state in the early stages the concept that contains the construction requirement, which would allow obtaining a higher level of success. However, all modifications and corrections required must be applied, surely delaying the project substantially, although allowing the completion of the work in a satisfactory manner.

\section{Certain aspects of ship design}

Each of these stages has a "defined function" in the project and in the design. For example, basic engineering allows having sufficient information for the technical and economical assessment of the project, its reliability, feasibility of construction and complexity from the engineering point of view. On the other hand, construction engineering involves details of the project that must be applied according to the shipyards, especially because not all shipyards operate in the same way, either due to training or resources. The problem arises in the early stages of the project, especially in the vague line that separates concept engineering from basic engineering.

The design of the ship, as it is the result of a set of specialties that are transformed into a product, requires the integration of such specialties through logical coordination, which at least is proposed and represented by what is known as the "design spiral"[1] (Fig. 1).

Fig. 1. Design Spiral

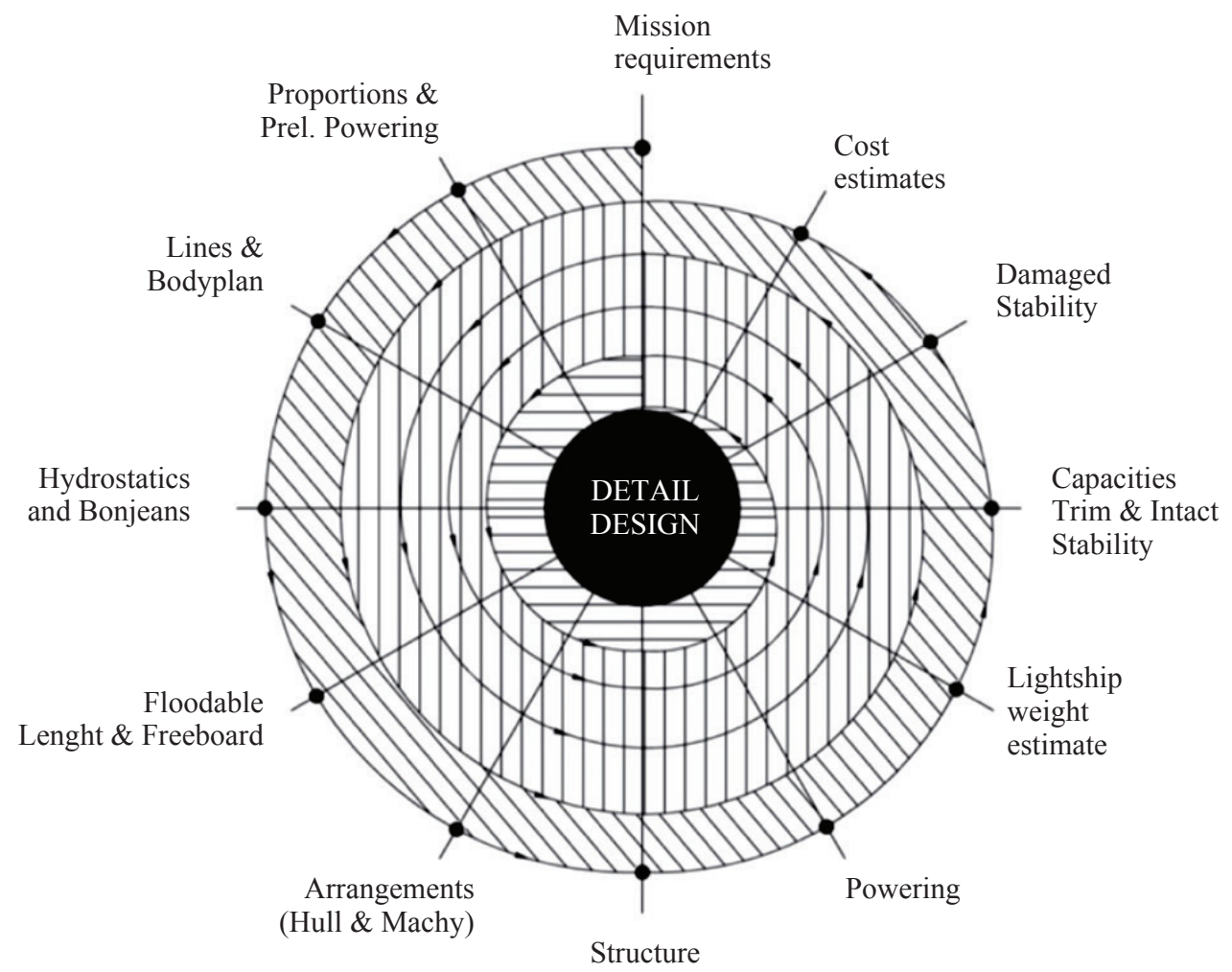


The "design spiral" is the most basic expression in the organization of a ship design, following the detail of each one of the process stages, the programming of the execution of works, either by means of a Gantt Chart or another system that allows adequate control, etc.

It is of special interest to refer to the critical design stages, such as for example the following:

a) Definition of the mission profile: It represents the life of the ship, which is closely associated with the participation of the shipbuilder. The proper definition of the mission profile, with the details required, will avoid later design problems.

b) Definition of forms: Stage associated with an adequate selection of the main dimensions, supported by a database based on the mission profile. The use of modern tools for the development of forms not only provides a high degree of accuracy, but also speed, allowing to provide a response within appropriate time frames.

c) Hydrodynamic studies: It is considered as one of the most complex stages where aspects that in many cases are contradictory are interwoven, for example, the relation of load capacity, hull volumes and speed. The use of numerical methods supported by tests carried out at marine hydrodynamic laboratories make this task one of the most representative of the world of naval architecture and the application of advanced tools.

d) Structural design: This stage is subordinated to hydrodynamic aspects and is very important in the design process, especially in ships with a special layout.

e) Estimation of costs: This stage allows determining the feasibility of a project, defining the size of the ship and the level of finishing, associated with the profitability sought by the shipbuilder.

\section{Concept engineering}

The concept engineering defines the subsequent development of the entire project, in the understanding that this stage will at least define the mission profile, the power to be installed on board, the general plan, preliminary weight estimation and certain preliminary costs.

The above can be discussed or not, depending on what is understood by concept engineering. Some authors define it as the first loop of the design spiral and the execution of which must be closely related to the shipbuilder. The problem arises when trying to define the line that divides concept engineering from basic engineering, since a "greater definition" of the concept will always be required before going to the next stage, which in many cases implies the conclusion or no of the design agreement. The number of engineering hours invested in this stage is difficult to quantify, depending on the type of ship and the work method of the design office or design department of the shipyard.

Fig. 2a shows concept engineering using the "design spiral" as a basis[2]. In turn, Fig. 2b shows a proposal regarding the order of priorities in the concept stage, while Fig. $2 \mathrm{c}$ shows the limits of all stages, concept engineering, basic engineering, contract engineering and detail engineering.

The level of depth of each one of the stages of concept engineering is subject to the resources available and the programmatic framework of the project, i.e. engineering hours are directly related to the project development program.

As indicated above, a deeper concept definition will allow the project to be developed more easily, since decisions regarding the concept will not be made in advanced stages of the project.

Table 1 shows the proposed scope of concept engineering. 
Fig. 2a. Concept engineering.

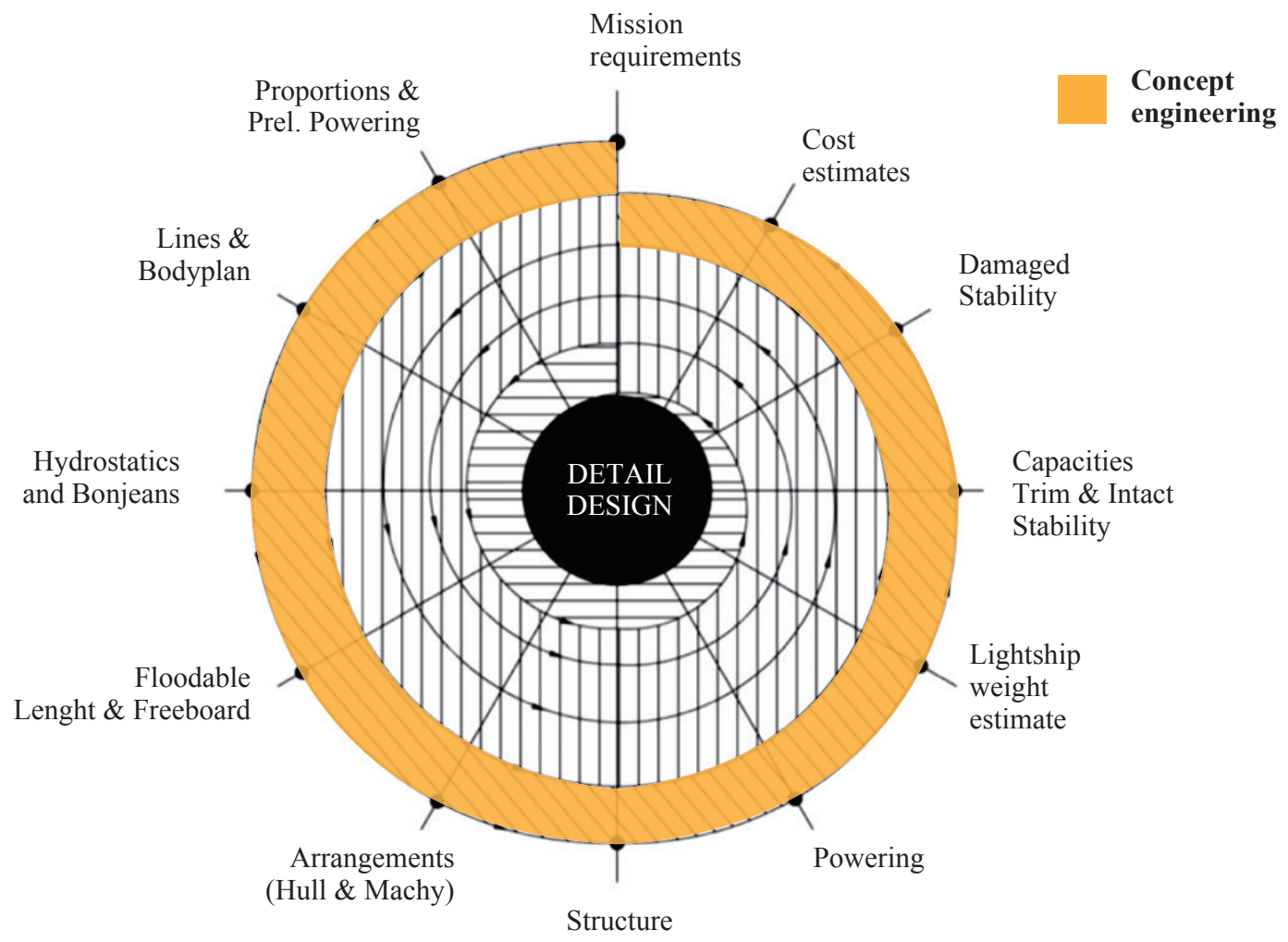

Fig. 2b. Order of priorities.

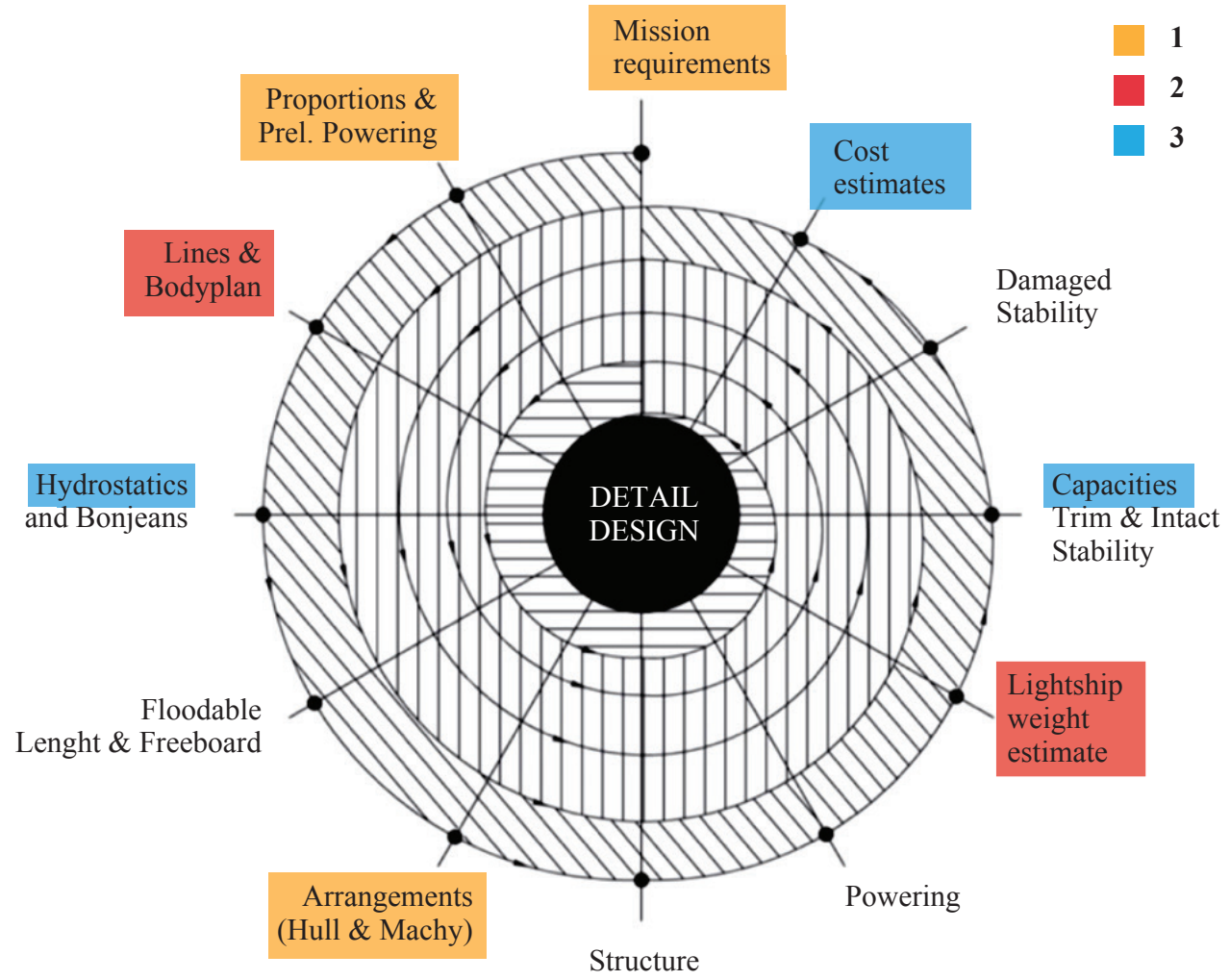


Fig. 2c. Limits of engineering stages.

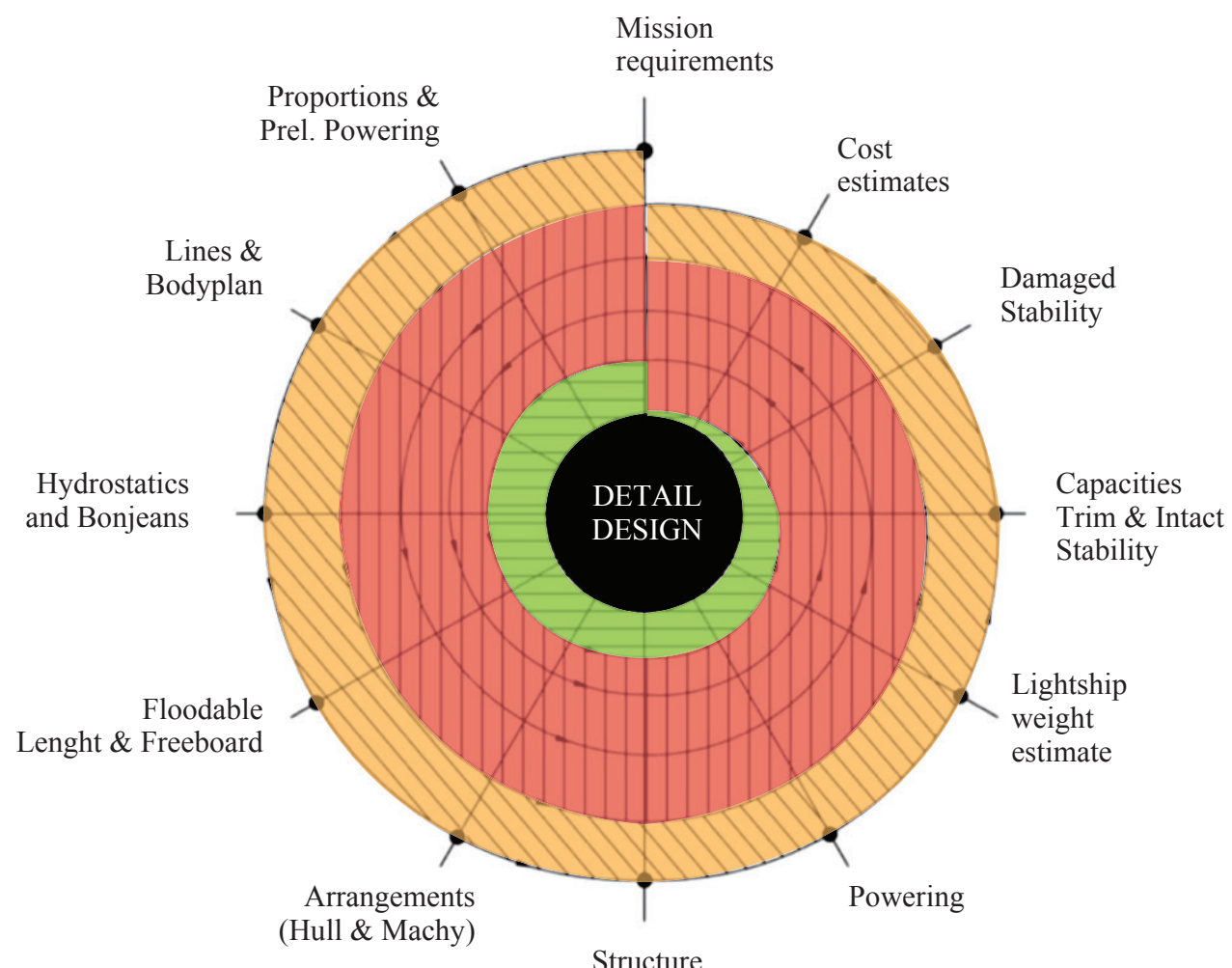

Table 1. Proposed scope of the concept engineering stage.

\begin{tabular}{ll}
\hline \multicolumn{1}{c}{ Stage } & \multicolumn{1}{c}{ Scope } \\
Mission Profile & $\begin{array}{l}\text { Definition of the purpose of the ship and its technical characteristics depending on the } \\
\text { area of operation, required capacities and specific needs to be met. }\end{array}$ \\
\hline Main dimensions & $\begin{array}{l}\text { Definition of the preliminary main dimensions using iterative methods and databases of } \\
\text { "similar ships". }\end{array}$ \\
preliminary forms & $\begin{array}{l}\text { Generation of the preliminary forms of the hull, adapting the necessary volumes and } \\
\text { the hydrodynamic characteristics associated with the mission profile, using approximate } \\
\text { methods for the definition of geometric coefficients. }\end{array}$ \\
\hline General layout & $\begin{array}{l}\text { Definition of the general plan based on construction requirements, complying with the } \\
\text { mission profile and considering a fine level of detail, which allows facing the rest of the } \\
\text { project with the ease of having detailed information. }\end{array}$ \\
\hline $\begin{array}{l}\text { Association of the preliminary estimate of power with the preliminary hull forms using } \\
\text { approximate methods and/or systematic series suitable to the type of ship. }\end{array}$ \\
$\begin{array}{l}\text { It is recommended to carry out a preliminary scantling based on the rules of } \\
\text { Classification Societies, drawing at least a sketch of the master frame, which allows } \\
\text { proposing the structural distribution based on this structure. }\end{array}$ \\
$\begin{array}{l}\text { An estimation of weights is made using approximate methods, correlating this stage } \\
\text { with the preliminary main dimensions and the development of forms, adjusting the } \\
\text { preliminary design draft and the estimated displacement. } \\
\text { estimation }\end{array}$ \\
$\begin{array}{l}\text { There are several approximate methods for estimating costs in the early stages of the } \\
\text { project, although the experience of the designer and the history of the shipyard will be } \\
\text { paramount at this stage. }\end{array}$ \\
\hline
\end{tabular}




\section{From theory to practice: case studies}

Projects usually go through a critical initial definition stage and are successful when they manage to overcome this stage and be fully developed. This section describes some critical and/ or breaking points in the conceptual development of successful projects.

\section{Main dimensions and work scale of the project}

The order, which in principle is very simple, deals with a recreational ship to be built in wood and which target image is the traditional (historical) ships of southern Chile. The original ships, as shown in Fig. 3, are only sailing boats and their mission profile is directed to work functions, but mixed propulsion is requested and its mission profile is mainly pleasure navigation.

The original main dimensions are circumscribed to what has been defined in templates from Europe. It has a length not exceeding 9 meters and with a running roof, which is only interrupted by a sliding hatch cover that allows access to the cargo and/or accommodation area, which in most cases is precarious. These ships have a generous beam and a sailplane composed of a larger main sail and a jib.

The mission profile, in this case, begins with the definition of accommodation requirements, which leads to estimating preliminary dimensions that exceed the traditional length. The first approach resulted in a length of 10 meters, considering a cabin with private toilet, a visitor cabin with capacity for three people, dining room, visitors toilet, full kitchen, crew cabin and engine room. The dimensions of the accommodations required by the shipbuilder require an increase in the length of the ship, being finally limited to 12 meters.

The main problem faced from the design point of view is the management of the scale required by the project, specifically in regards to indoor spaces and of course the handling of rigging, maneuverability and rudder, structural design and equipment on board, considering that it is a ship constructed using artisan methods and which dimension rations are outside the ranges normally used.

From the theoretical point of view the project does not pose major difficulties, but from the practical point of view it faces two aspects that must be considered: the construction system and the finishing level required by the shipbuilder, which are not traditional in an artisanal ship. The concept engineering presented to the shipbuilder was limited to aesthetic aspects, both exterior and interior, which in many points of the project resulted contradictory with other requirements. However, it was possible to bring the concept to reality, as shown in Fig. 4.

Fig. 3. Original ships.
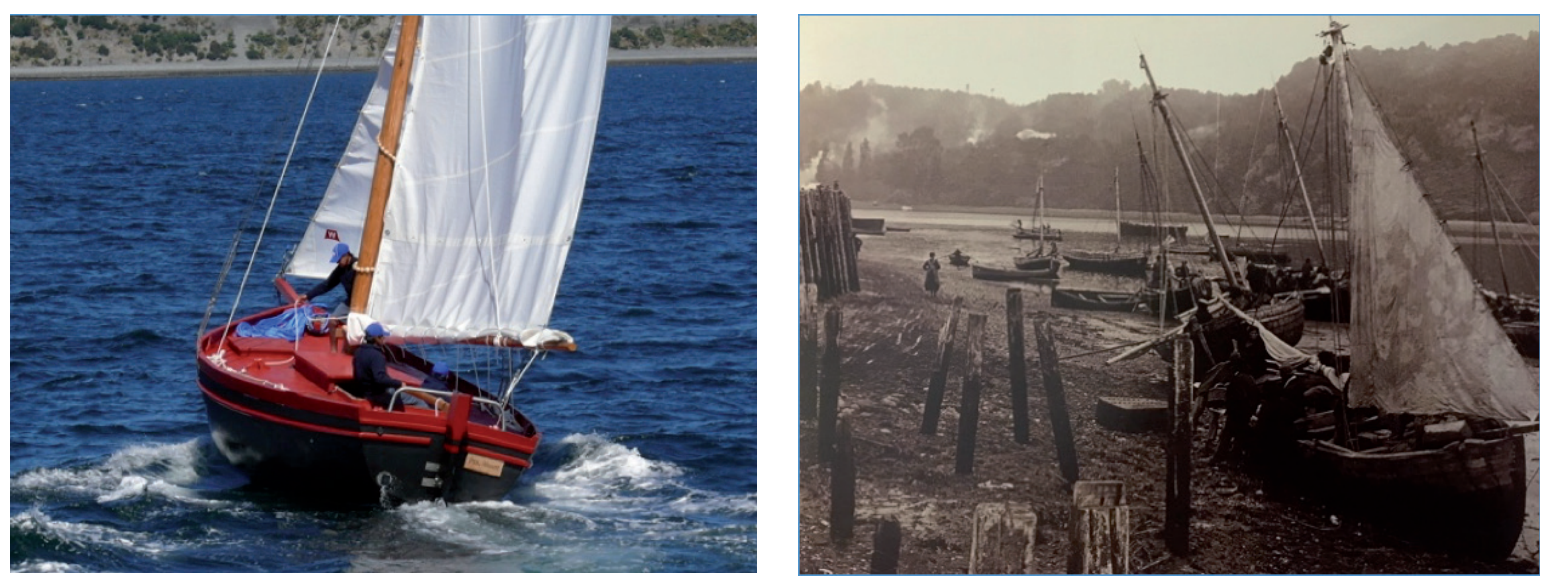
Fig. 4. Full-scale ship.

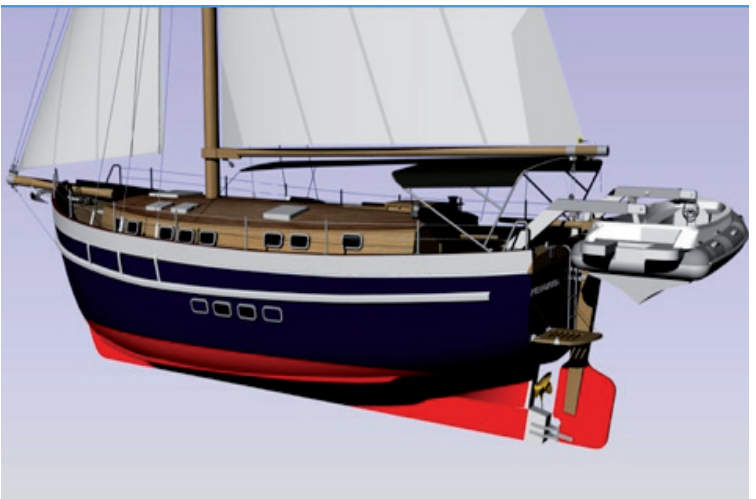

Compromise solution for support ship

The order arises from the need of the shipbuilder to have a boat that must mainly fulfill two roles, in addition to the normal roles of a ship. It must be considered that in naval architecture the definition of "multipurpose" restricts the project in some areas to enhance others. The project presents a ship that will perform tasks such as LEP and REM, highlighting the difficulty of combining the values required by the standard in certain aspects, for example the freeboard and the heel at the time of the pulling action.

The design process focused on two aspects:

a) Design of forms

b) Strength and position of the pulling point associated with stability criteria

These two aspects are directly related to the requirements of the Maritime Authority, regarding the criteria of stability and what has been defined in the Rules of Classification Societies as the method for calculating the heeling moment.

The methodology used consisted of a calculation matrix composed of the parametric variation of the ship's beam, force and pulling position. The flooding angle was defined as a constant in the analysis, considering that the hull models were adjusted, thus achieving a considerable reduction in the models to be studied.

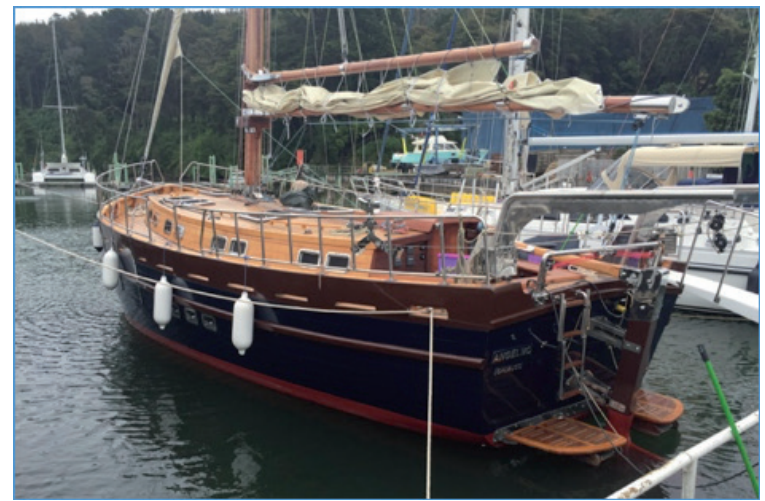

Table 2 shows the main features of the ship.

Table 2. Main characteristics of the ship.

\begin{tabular}{lr}
\hline \multicolumn{1}{c}{ Characteristic } & \multicolumn{1}{c}{ Unit (m) } \\
\hline Total length & 16.50 \\
\hline Maximum beam & 5.20 \\
\hline Moulded depth & 3.15 \\
\hline
\end{tabular}

Fig. 5 shows the general planimetry of the ship during its finishing phase.

In theoretical terms, compliance with stability criteria can be covered in the design stage. Although it implies a laborious analysis process, the objective of the mission profile was achieved in this stage. In practical terms, a careful control of weights is required during the construction process, ensuring that the modifications are the minimum possible so as not to alter the draft or trim of the ship. There are other restrictions and requirements arising from concept engineering associated with regulatory requirements, thus making the project complex and requiring thorough control on each stage.

\section{Prediction of failures in design stages}

Sailing ships pose design challenges additional to propelled ships. In this case, the ship is a mini-coastal vessel 6 meters in length. From the theoretical point of view, the design is framed in traditional lines but with a greater hull volume, 
Fig. 5. General planimetry and finishing phase.
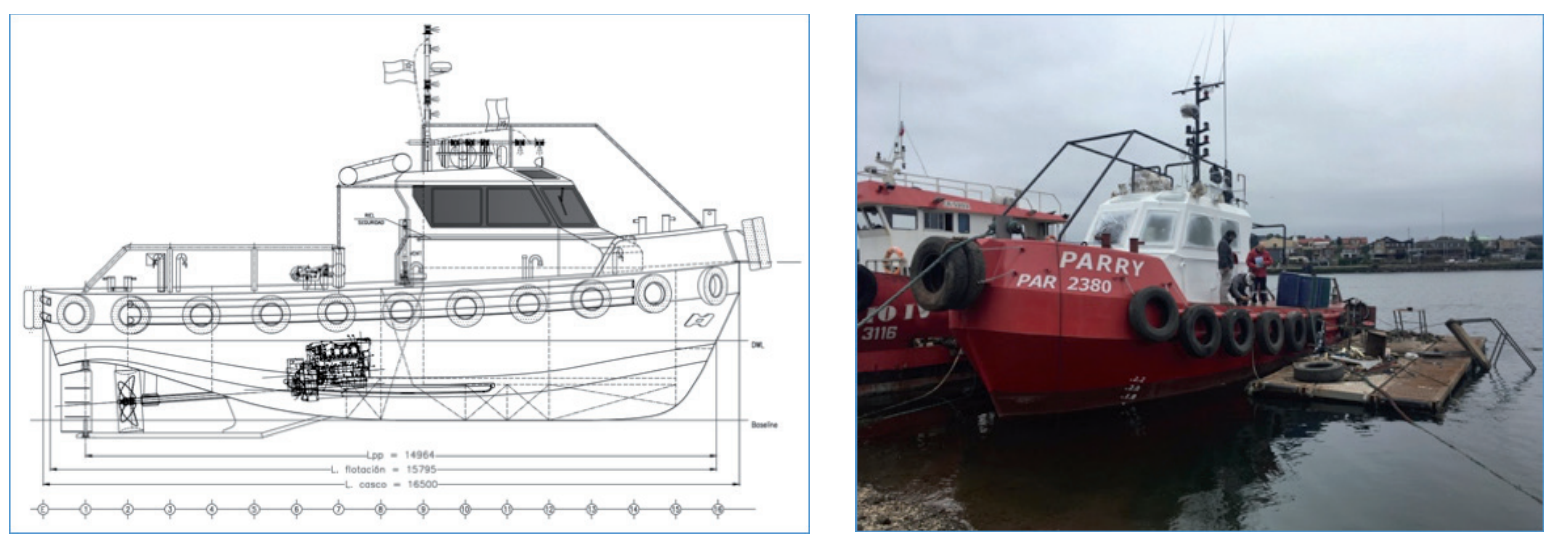

which provides a generous freeboard for this boat size segment. The need to provide the boat with a safety range that will allow it to face demanding regattas resulted in the improvement of the position of the ship's center of gravity with respect to the original design and in the redesign of the sailplane. The structure broadly complies with what was proposed by the Classification Societies and the yacht design literature.

Fig. 6 shows what was built and installed on the ship and Fig. 7 [3] shows the failure area that takes place in the case of a "forced" maneuver with a spinaker.

Fig. 6. Built part of the ship.

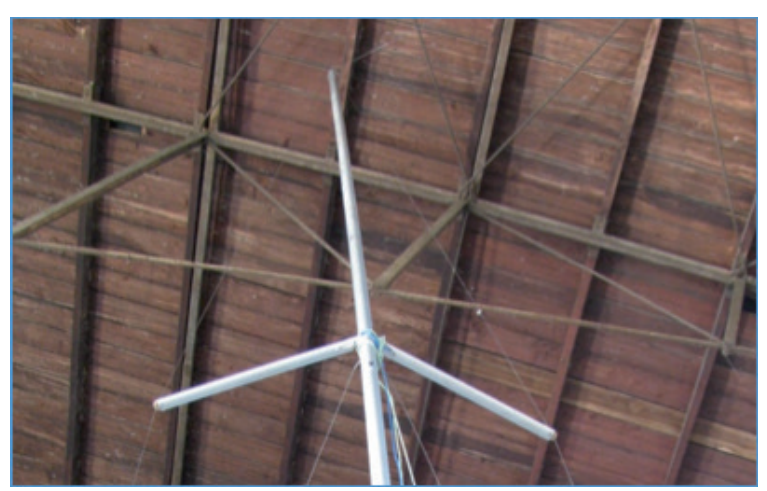

The prediction of the structural behavior of the different component parts of the ship, allow, among other things, recommending the operation of the ship by limiting some maneuvers in order to avoid possible structural failures.
Fig. 7. Failure area.

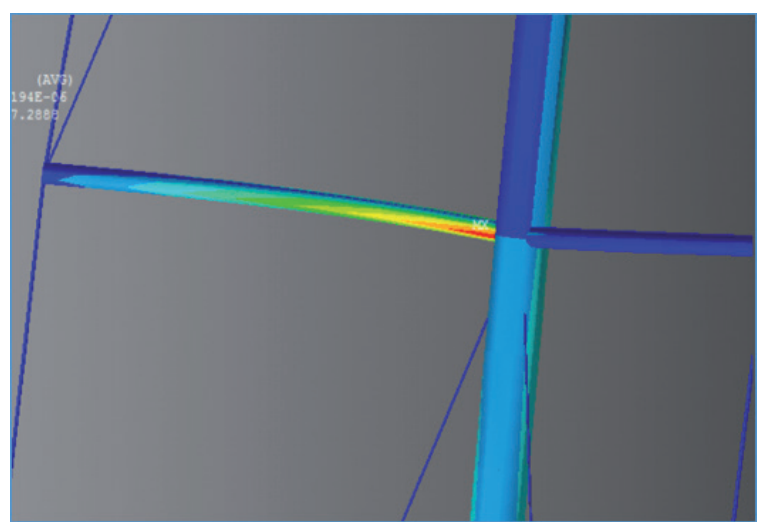

In theoretical terms, a load condition was defined that would cause mast failure. This load condition is produced by a forced maneuver of the spinaker. In practical terms, this was fully demonstrated by removing the mast while navigating, which is shown in Fig. 8.

\section{Conclusions}

Although the initial notes and the cases presented are specific and limited to small ships,[4] the experience of going from theory to practice can be extrapolated to larger ships and naval artifacts, especially in relation to conceptual engineering. The implementation of state-of-the-art tools to simulate the behavior of the ship in the different design stages, either through numerical codes for the simulation of flows around the hull or the 
Fig. 8. Removed mast.

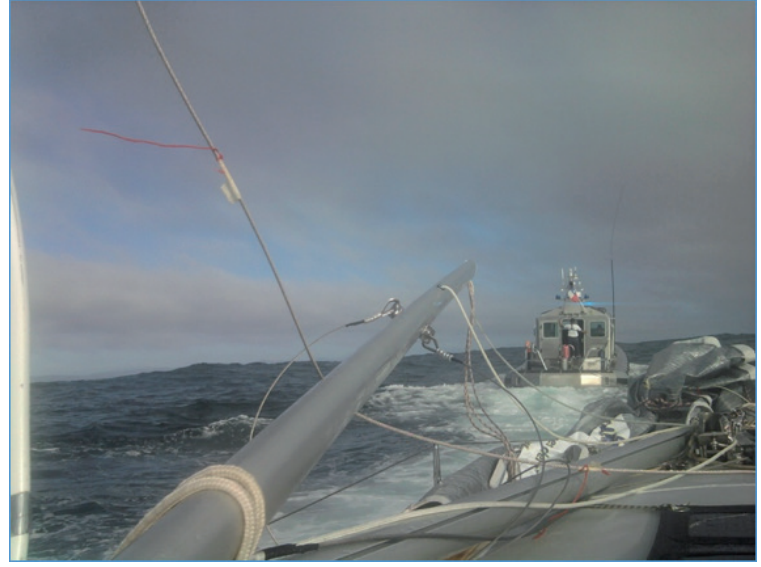

structural behavior of the hull, allow narrowing the distance between theory and practice.

\section{References}

[1] PAPANIKOLAOU, A. Ship Design, Methodologie of preliminary design. Springer Science Business Media (2014).

[2] ALVARIÑO, R. AZPIROZ, J. MEIZOSO, M. El Proyecto básico del buque mercante.

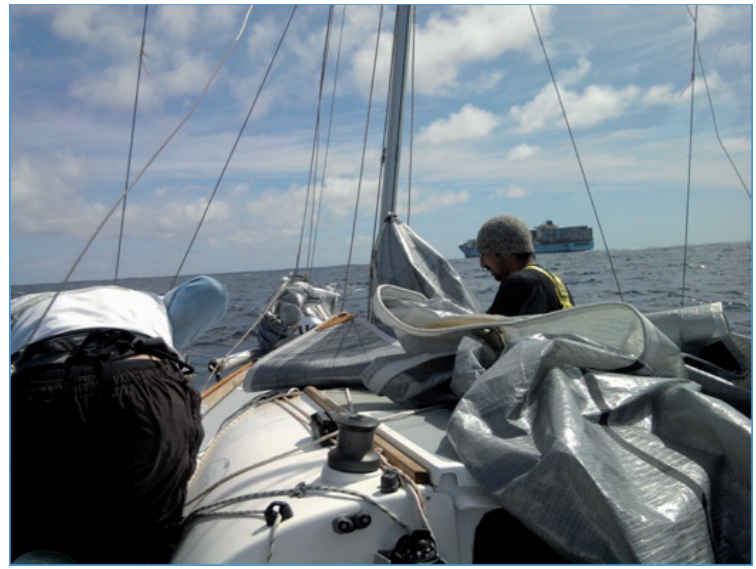

Fondo editorial de Ingeniería Naval, Madrid (1997).

[3] BENARD, J. Coursework report - Soton - UK (2015).

[4] FLORES, R. BAOS, R. Diseño NT_451 (2018) - NCH_068 (2001) - NT_233 (2014-16). 
